\title{
The relationship of water and salt
}

\section{By J. R. Elkinton*, Chemical Section of the Department of Medicine, University of Pennsylvania School of Medicine, Philadelphia, U.S.A.}

In the preceding paper Dr Robinson (1957) has presented a graphic picture of the functions of water in the body. He has sketched its suitability as a milieu in which the metabolic processes of living cells can take place, its dependence on various osmotic forces in respect to its internal movements, and the fine adjustment of its exchanges with the external environment through the mechanisms of thirst and secretion of antidiuretic hormone. Dr Robinson concluded, however, by pointing out that the total amount or volume of water in the several main compartments of the body depends, in the end, upon the total amount of the principal ionic solute sodium, in that tight-fitting pond, the extracellular fluid. It becomes clear, therefore, that on the biological as well as on the geochemical level any consideration of the function of water requires also consideration of the principal constituents or salts that are dissolved in that water. Hence the necessity in this symposium on the subject of water of directing our attention for a few moments to the subject of salt.

\section{Ionic patterns in body water}

The first and perhaps most important fact to be emphasized is that the kinds and relative proportions of the electrolytes or ionized salts in the pond or extracellular fluid are almost completely different from those in the fluid inside the body cells. In Table I, columns 4 and 5 , are shown the concentrations of positively charged ions,

Table $\mathrm{x}$. Cationic concentrations in ancient and present-day sea-water and in vertebrate body fuids

\begin{tabular}{|c|c|c|c|c|}
\hline \multirow[b]{2}{*}{ Cation } & \multicolumn{2}{|c|}{ Sea-water } & \multicolumn{2}{|c|}{ Vertebrate body fluids } \\
\hline & Mid pre-Cambrian & Present day & Extracellular & Intracellular \\
\hline $\mathrm{Na}$ & 298 & 478 & I 44 & 10 \\
\hline $\mathrm{K}$ & 104 & 10 & 5 & 161 \\
\hline $\mathrm{Mg}$ & I I & 55 & 2 & 26 \\
\hline $\mathrm{Ca}$ & 2 & I I & 5 & 2 \\
\hline Total & 4I 5 & 554 & 156 & I 99 \\
\hline
\end{tabular}

or cations, in the extracellular and intracellular phases of body water. The major differences between the two types of fluid are at once apparent; extracellular fluid is predominantly a solution of sodium (with chloride and bicarbonate), intracellular fluid of potassium and magnesium (with phosphate and protein). Since the anionic

*Established Investigator of the American Heart Association on leave from the University of Pennsylvania at the Medical Research Council Department of Experimental Medicine, University of Cambridge. 
content is always adjustable by the ever-available bicarbonate, the total concentration in each fluid is primarily determined by the cations; thus it can be said that the major extracellular solute is sodium, the major intracellular solute is potassium. The differential distribution of these two substances, sodium and potassium, is a basic biological phenomenon and merits our attention for a few minutes as to how it came about.

Salt and water in the paleochemistry of the earth and the evolution of body fluids

The similarity of the ionic pattern of extracellular fluid to that of sea-water immediately becomes apparent when columns 3 and 4 in Table I are compared. True, the total concentration of salt in sea-water is between three and four times as great as that in extracellular fluid, but both are predominantly solutions of sodium salts and both contain very little potassium. This similarity readily leads to the thought that Dr Robinson's (1957) tight little extracellular pond was once the wide, wide sea. This suggestion was first made by Bunge in Germany in I 889 (Bunge, 1889) and was extended by Macallum in 1903 and again in 1926 (Macallum, I904, I926) to the hypothesis that the composition and total ionic concentration of vertebrate extracellular fluid is a heritage of the ancient seas in which these organisms first evolved. In a word, when the need developed for a private and stabilized internal environment, the extracellular pond was but a small bay cut off from the wider and older environment, the sea. This hypothesis of Macallum's has had to be modified in the light of more recent studies of the paleochemistry of the earth, the chemical evolution of the oceans, and the evolution of osmoregulatory mechanisms in response to widely varying environments. But there remains little doubt that the composition of present-day extracellular fluid reflects a marine ancestry.

When one considers the progressive modification of the earth's crust and the chemical evolution of the oceans over geological time, a fascinating story unfolds of the sequestration or separation of sodium from potassium on a geochemical as well as on a biological level (Conway, 1942, 1943). In Table 2 are shown some of Conway's values for the relative cationic content of igneous rock, ocean water, and

Table 2. Relative cationic composition of igneous rock, ocean water, and total surface rock

$\begin{array}{lccc}\text { Cation } & \begin{array}{c}\text { Igneous } \\ \text { rock }\end{array} & \begin{array}{c}\text { Ocean } \\ \text { water }\end{array} & \begin{array}{c}\text { Total surface } \\ \text { rock* }\end{array} \\ \mathrm{Na} & 100 & 100 & 100 \\ \mathrm{~K} & 54 & 2 & 133 \\ \mathrm{Mg} & 142 & 23 & 334 \\ \mathrm{Ca} & 146 & 5 & 454\end{array}$

Modified from Conway (1942, 1943); values are expressed as equivalents per I 00 equivalents of sodium. ${ }^{*} 75 \%$ sedimentary rock.

total surface (mainly sedimentary) rock. Quite clearly, as the rains of heaven dissolved the original igneous rock of the earth's surface, washing the solutes into the sea where sedimentary rock was formed by precipitation, a definite separation, or 
differential distribution of the cations took place. Sodium remained in solution in the sea-water, whereas potassium, magnesium and calcium became concentrated in the sedimentary rocks. The removal of potassium from sea-water has been both relative and absolute in respect to sodium. Conway has calculated the changes in concentration of various major ions in the ocean that have taken place over geological time. The cationic concentrations in the mid pre-Cambrian ocean are compared with those in present-day sea-water in Table I. Sodium and chloride (if the latter was of volcanic origin) have steadily accumulated whereas the potassium content increased to a much lesser extent during pre-Cambrian times, and subsequently has absolutely, as well as relatively, diminished; calcium and magnesium have for the most part been precipitated as carbonates and sulphates. Rough calculations indicate that the oceans of the world now contain approximately I4I geograms $\left(\mathrm{I} 4 \mathrm{I} \times 1 \mathrm{IO}^{20} \mathrm{~g}\right.$ ) of sodium ion, and some roo geograms of potassium have been deposited in sedimentary rock, principally the clay minerals, illite and glauconite.

The mechanism of this stupendous chemical operation is essentially unknown. Conway has suggested that the more ready penetration of potassium into the negatively charged silica sheets of the illite lattice is related to the fact that the diameter of the hydrated ion of potassium is smaller than that of sodium. This is a property that has also been invoked to explain the greater penetration of potassium into the negatively charged protein lattice of the living cell. Such a biological process may indeed be involved in the geochemical separation since the potassium-rich mineral, glauconite, is formed from the shells of dead foraminifera; and this in turn may be the explanation of the increased rate of removal of potassium from the sea as living organisms proliferated in the late pre-Cambrian era. But whatever may be the mechanisms responsible, the central fact is clear that sodium and potassium are distributed differentially in geochemical as well as in biological systems, sodium accruing to the sea and to extracellular fluid, potassium to the soil and to the cell. As Fenn (1940) has put it so succinctly, 'potassium is of the soil and not of the sea; it is of the cell and not of the sap'.

In this setting of biological and geochemical interplay, remarkable for its ubiquity in time and space, the fortunes of water can seldom be separated from those of salt. The story of evolution of vertebrate organisms and their adaptation to the vicissitudes of an ever-changing environment (Smith, 1953) can hardly be told here. But our theme that the fortunes of water and salt are linked is a central one in this story, for the evolving organisms were constantly under the necessity of defending their osmotic integrity against wide variations in the osmolarity, i.e. water: salt ratio, of the external environment. Life in the hypotonic medium of fresh water where overhydration was ever a threat, led to the development of such mechanisms as watertight skins which actively and selectively absorbed salts, and glomerular kidneys which excreted copious hypotonic urines. Return to a marine existence in the hypertonic seas, which threatened dehydration, led to a variety of functional adaptations: the physiological uremia of the marine elasmobranchs, the salt-secreting gills of the marine teleost fishes, and the water-conserving kidneys of the marine mammals. In life on dry land and in the air the defence against desiccation resides primarily in 
that key organ, the kidney, which in birds and mammals has developed the power to elaborate a hypertonic urine and so to conserve water in relation to solute. In man, therefore, it is the kidney that is pre-eminently the organ of regulation of salt and water balance and the guardian of the composition of our internal pond and its cellular contents.

\section{Basic physiological problems of electrolyte and water interrelationships}

With this background of paleoecology in mind, we are now in a position to state, but not to answer, two of the major physiological problems of water and salt metabolism which face biologists today. The first of these is: what are the physicochemical or biochemical mechanisms which are responsible for the maintenance in a steady state of this differential distribution of potassium inside the cell and sodium outside the cell? The second question is : how does the total organism maintain the constant relationship of water and salt, and the total volume of these two main phases of the body fluids?

With the space at hand we cannot even outline the major investigations of these physiological problems. Much is being done on the physicochemical properties of the cell that encourage the penetration and retention of potassium as compared with sodium ions. A large amount of evidence points to the conclusion that the differential movements of these ions across the cell boundary requires energy derived from metabolic processes within the cell; studies of 'sodium pumps' and 'potassium pumps' are the order of the day. The second question, namely how the total amount of salt and hence of water in the body is regulated, is one that was passed directly on to me by Dr Robinson (1957). This question may be stated a little more succinctly: how does the kidney know how much sodium and potassium to excrete? At present there are many clues but no definite answers to this question. On the afferent side of such a regulatory arc evidence has been adduced that there are 'volume receptors' stimulated by changes in volume of, or pressure in, one or more portions of the body fluids, such as of plasma, interstitial fluid, or in cardiac output or renal blood flow. The sites of such receptors have been variously placed in the head, the thorax and the extremities. On the efferent side interest has been divided between a neural and humoral pathway to the kidney. Currently, a series of studies indicates that the adrenocortical hormone, aldosterone, plays an important part in regulating the renal tubular reabsorption, and therefore the renal tubular excretion, of both sodium and potassium. But even if this be so, we still do not know what tells the adrenal cortex how much aldosterone to secrete. There are still worlds to conquer!

\section{Examples of the dependence of the distribution of water on that of salt}

In this final section I wish to give a few examples of the dependence of water distribution on that of salt, more particularly sodium. The relation of cellular water to cellular potassium is a more complex one depending as it does upon the intricacies of cellular anabolism and katabolism; examples of this I will leave to subsequent speakers. Extracellular sodium, however, is readily accessible to experimental 
manipulations, and the following simple studies were conducted with my colleagues in Dr John P. Peter's laboratory at Yale more than a decade ago (Elkinton \& Taffel, 1942; Hopper, Elkinton \& Winkler, I944; Winkler, Elkinton, Hopper \& Hoff, 1944).

Let us first consider the effect on a deficit of water of the presence or absence of a concurrent deficit of sodium. When a dog is deprived of drinking water he sustains a steady loss of body water through vaporization in his lungs in conjunction with the obligatory dissipation of body heat. The renal response to such a pure water loss, the 'dehydration reaction', appears to be that, despite rising concentrations of sodium and chloride in extracellular fluid, these ions tend to disappear from the urine while the concentration of potassium is tremendously increased. We know now that this must be the effect on the kidney of a tremendously augmented secretion of aldosterone. But even then the results of this renal response were quite apparent. The deficit of body water, already distributed between extracellular and intracellular phases, was minimized in the former at the expense of the latter by the kidneys' retention of sodium rather than potassium. Teleologically, this may be interpreted as a mitigation of the loss of extracellular fluid, with its dire circulatory sequelae, at the expense of cellular water. This biphasic distribution of the experi-

\section{Table 3. Percentage changes in body water experimentally produced in the dog}

$\quad$ Body
$\quad$ water
Extracellular
Intracellular
Total

Effect

$\begin{gathered}\text { Water } \\ \text { deprivation } \\ -25 \\ -24 \\ -25\end{gathered}$

Circulatory
failure

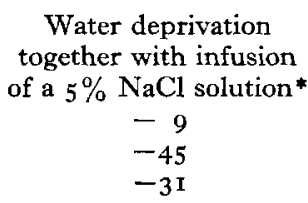

Respiratory failure

From the data of Hopper et al. (1944) and Elkinton \& Winkler (1944).

* Simulating ingestion of sea-water.

mental water loss is shown in column 2 of Table 3 . In contrast, the effect of the experimental withdrawal of sodium in excess of water is shown in column 3 : the total ionic concentration in the extracellular fluid then falls, water moves into the cells, and the entire deficit is borne by the extracellular compartment. Despite the fact that the total water loss is only $10 \%$ as compared with $25 \%$ in the dehydrated $\mathrm{dog}$, the relative contraction of extracellular fluid is greater and the concomitant circulatory collapse is far more serious in nature. In many environmental and clinical situations in which man finds himself, maintenance of his body and with it a relatively normal circulation and volume of fluid in his extracellular compartment, is a central factor in his survival.

The final example relates to the role of sodium in another stressful and distressing situation, that of the castaway at sea. It has long been suspected, and recently thoroughly documented by McCance and his associates (McCance, Ungley, Crosfill $\&$ Widdowson, 1956), that the ingestion of sea-water carries with it a high mortality rate. The concentration of sodium in sea-water is considerably in excess of the 
ability of the human kidney to concentrate sodium in the water available for excretion. In column 4 of Table 3 is shown the effect in a dog of the experimental simulation of sea-water ingestion, that is the addition of sodium in excess of water. The concentration of extracellular sodium rose abruptly, water was rapidly withdrawn from body cells, and respiratory failure ensued. Too much, as well as too little, sodium in relation to water can be a bad thing!

\section{Conclusion}

My children once asked me what my colleague, Dr T. S. Danowski, and I were writing about when we were laboriously compiling a monograph under the title The Body Fluids. My answer was that our subject might just as well be entitled, Peter Rabbit in the Pond and the Pond in Peter Rabbit, a description independently arrived at by Dr Robinson. My share in this symposium has been to make the point that despite the predominantly watery character of ponds the health and happiness of Peter Rabbit depends on how those ponds are salted.

\section{REFERENCES}

Bunge, G. ( 1889 ). Lehrbuch der Physiologischen und Pathologischen Chemie. Leipzig.

Conway, E. J. (I942). Proc. R. Irish Acad. 48, sect. B, p. I I9.

Conway, E. J. (1943). Proc. R. Irish Acad. 48, sect. B, p. I6I.

Elkinton, J. R. \& 'Taffel, M. (I942). F. clin. Invest. 2I, 787.

Elkinton, J. R. \& Winkler, A. W. (1944). War Med., Chicago, 6, $24 \mathrm{I}$.

Fenn, W. O. (1940). Physiol Rev. 20, 377.

Hopper, J. Jr., Elkinton, J. R. \& Winkler, A. W. (1944). F. clin. Invest. 23, I I 1.

Macallum, A. B. (1904). Trans. R. Canad. Inst. 7, 535.

Macallum, A. B. (1926). Physiol. Rev. 6, 316.

McCance, R. A., Ungley, C. C., Crosfill, J. W. L. \& Widdowson, E. M. (1956). Spec. Rep. Ser. med. Res. Coun., Lond., no. 291.

Robinson, J. R. (1957). Proc. Nutr. Soc. 16, 108.

Smith, H. W. (1953). From Fish to Philosopher. Boston: Little, Brown and Co.

Winkler, A. W., Elkinton, J. R., Hopper, J. Jr. \& Hoff, H. E. (1944). F. clin. Invest. 23, 103.

\section{Water equilibrium in health}

\section{By Elsie M. Widdowson, Medical Research Council Department of Experimental Medicine, University of Cambridge}

Dr Robinson (I957) and Dr Elkinton (1957) have described how all the chemical reactions of the body by which life is maintained take place in a watery medium, and made it clear that life without water is impossible. They have stressed how important it is that the extracellular fluids--the pond in fact-shall remain constant in volume and composition. Ponds, however, tend to dry up, and the one in the body is losing water every minute of the day and night; these losses must be made good if life is to proceed in the normal way.

Fresh supplies of water are obtained from three main sources. The first is fluids that we drink, and man generally drinks more than he needs. This is not true of an 